Bülent Barış Güven ®

Fulya Yurtsever $\odot$

Temel Güner ๑

Sedat Temircan $\odot$

Ömer Bakal ๑

Ayşın Ersoy ๑

\title{
A Case of Herpes Zoster Following an Epidural Steroid Injection
}

öz

Herpes zoster arka kök ganglionlarında latent olarak kalan Herpes zoster virüsün, özellikle malignite, enfeksiyon, steroid kullanımı veya kronik böbrek yetmezliği gibi bağışıklık sisteminin baskılandığı durumlarda reaktivasyonu sonucu oluşur. Bunların bir kısmında çok ağrıı seyreden post herpetik nevralji (PHN) tablosu gelişir. Literatürde PHN'nin tedavisi için epidural steroid kullanımına dair pek çok yayın varken paradoksal bir şekilde steroid enjeksiyonuna bağlı gelişen PHN yalnızca 2 olguda bildirilmiştir. Bu makalede, lumbar spinal stenozun neden olduğu bel ağrısı nedeniyle epidural steroid uygulanan kronik böbrek yetmezlikli hastadaki Herpes zoster tablosu sunuldu.

Anahtar kelimeler: Herpes zoster, epidural steroid, postherpetik nevralji

\section{ABSTRACT}

Herpes Zoster occurs as a result of reactivation of Herpes zoster virus, which remains latent in the posterior root ganglia, especially in cases where the immune system is suppressed, such as malignancy, infection, use of steroidal drugs or chronic renal failure. In some of these cases a very painful postherpetic neuralgia (PHN) develops. While there are many publications on the use of epidural steroids for the treatment of PHN in the literature, in a paradoxic way, PHN induced by steroid injection has been only reported in 2 cases. In this article, a case of herpes zoster in a patient with chronic renal failure who underwent epidural steroid treatment for low back pain caused by lumbar spinal stenosis is reported.

Keywords: Herpes zoster, epidural steroid, postherpetic neuralgia

Alındığı tarih: 31.01 .2019

Kabul tarihi: 04.03.2019

Yayın tarihi: 30.04 .2019

Atıf vermek için: Güven BB, Yurtsever F, Güner T, Temircan S, Bakal Ö, Ersoy A. Epidural Steroid Enjeksiyonu Sonrasında Gelișen Bir Herpes Zoster Olgusu. JARSS 2019;27(2):139-42.

Bülent Barış Güven Sultan Abdulhamidhan Eğitim Araştırma Hastanesi, Anestezi Servisi, İstanbul, Türkiye barguv@gmail.com ORCID: 0000-0002-3628-7408

F. Yurtsever 0000-0001-6180-0050 T. Güner 0000-0002-5910-2277

S. Temircan 0000-0003-4220-7627

Ö. Bakal 0000-0002-9740-2131

A. Ersoy 0000-0002-1575-1603 Sultan Abdulhamidhan Eğitim Araştırma Hastanesi, Anestezi Servisi, istanbul, Türkiye

\section{Giriş}

Hastaların sosyal yaşamında ciddi kısıtlamalara yol açan bel ağrısının en sık nedenlerinden birisi lumbar spinal stenozdur ve en sık nedeni yaşlanmaya bağlı dejenerasyondur ${ }^{(1)}$. Tedavide öncelikle yatak istirahati, ilaç tedavisi ve fizik tedavi gibi konservatif yaklaşımlar denenmelidir. Ancak konservatif tedaviye dirençli hastalarda, ağrının giderilmesinde epidural steroid enjeksiyonu sık kullanılan ve düşük riskli bir tedavi seçeneğidir. Epidural enjeksiyonların bel ağrılarının tedavisinde ilk olarak kullanımı 1930 yılında Evans tarafından tanımlanmıştır (2). Epidural steroid enjeksiyonunun sık görülen komplikasyonları; baş ağrısı, lokal hematom, kanama, araknoidit, hiperglisemi, bel ağrısında artış, epidural lipomatozis, Cushing sendromu, yüzde flushing, Horner sendro- mu, adrenal supresyon, vazovagal reaksiyonlar, bulantı ve ateştir ${ }^{(3)}$. Herpes Zoster (HZ) enfeksiyonu ve buna bağlı gelişen postherpetik nevralji (PHN) de daha nadir olmakla birlikte, bu komplikasyonlar arasında yer almaktadır. Literatürde PHN'in tedavisi amacıyla epidural alana steroid enjeksiyonu yapıldığını bildiren birçok yayın varken, bu uygulamanın bir komplikasyonu olarak $\mathrm{HZ}$ oluştuğunu bildiren yalnızca 2 olgu raporu belirledik ${ }^{(4,5)}$. HZ virüs arka kök ganglionlarında latent olarak kalır ve immun sistemin baskılandığı durumlarda reaktivasyon sonucu akut bir enfeksiyona neden olabilmektedir. Akut $\mathrm{HZ}$ enfeksiyonu tipik dermatomal ağrı ile başlar ve zamanla ağrı kronikleşebilir. HZ enfeksiyonunun en sık görülen nörolojik komplikasyonlarından biri olan PHN, kronik bir ağrı sendromudur ${ }^{(6)}$. 


\section{OLGU SUNUMU}

Kronik Böbrek Yetmezliği (KBY) nedeniyle yaklaşık 7 yıldır haftada 3 gün rutin hemodiyalize giren ve hipertansiyon tedavisi alan, BMI:21 (B:155 cm, K:51 $\mathrm{kg} \mathrm{m}^{-2}$ ) olan, 73 yaşındaki kadın hasta bir haftadır ağrı kesici ilaçlara rağmen devam eden, sağ tarafta daha fazla olmak üzere, her iki bacak ağrısı şikayetiyle polikliniğe başvurdu. Kladikasyo bulguları olan hastanın yapılan nörolojik muayenesinde, bilateral tibialis anterior kas gücü $4 / 5$ idi ve sağ L4-L5 dermatomlarında hipoestezi mevcuttu. Lomber MR ve direkt grafileri incelendiğinde hastada L4-L5 intervertebral disk seviyesinde ciddi spinal stenoz izlendi. Ameliyat kabul etmeyen hastaya ağrı tedavisi için epidural steroid enjeksiyon uygulaması planlandı.

Olgudan uygulanacak işlemler ve tıbbi bilgilerinin kullanımı için gerekli onamlar alındıktan sonra hastaya sağ el sırtından intravenoz damaryolu açıldı ve hasta monitorize edildi. Oturur pozisyonda işlemin planlandığı alana $2 \mathrm{~mL} \% 2$ lidokain ile bölgesel anestezi uygulandıktan sonra, L4-L5 seviyesinden $18 \mathrm{G}$ Tuohy iğnesi ile orta hattan interlaminar yaklaşım kullanılarak epidural aralığa girildi. Subaraknoid aralığa girilmediğinden emin olunduktan sonra $80 \mathrm{mg}$ metilprednizolon, $2 \mathrm{~mL} \% 2$ lidokain ve $6 \mathrm{~mL}$ serum fizyolojik ile birlikte uygulanacak ilacın toplam hacmi $10 \mathrm{~mL}$ 'ye tamamlanarak enjekte edildi. İşlemden 24 saat sonra hastanın VAS ağrı skoru, enjeksiyon öncesine göre \%50'den daha fazla oranda azalma gösterdi. İşlemden 72 saat sonra ise hastanın bel ağrısı şikayeti tamamen kayboldu. Bir hafta sonra hastanın yapılan kontrol muayenesinde, sağ alt torakolomber bölgesinde ağrı ile birlikte eritemli zeminde kaşıntılı çok sayıda vezikülobüllöz lezyonlar görüldü (Şekil 1).

Dermatoloji Kliniği ile konsülte edildikten sonra, hastada $\mathrm{HZ}$ enfeksiyonu geliştiği belirlendi. Bunun üzerine hastaya tedavi için oral valasiklovir, $B_{12}$ vitamini, setirizin, parasetamol başlandı, sulantılı cilt lezyonlarına eauborique solüsyon, kuru ve kabuklu cilt lezyonlarına topikal mupirosin uygulandı. On gün sonra yapılan muayenesinde lezyonlardaki kaşıntının azaldığı ve üzerlerinin kabuklandığı görüldü. Sorgulandığında bel bölgesi ve bacaklarında ağrısı olmayan hastanın HZ enfeksiyonuna bağıı ağrısının devam ettiği anlaşıldı. Mevcut ağrısının PHN nedeniyle geliştiği düşünülerek hastaya oral 2'ye bölünmüş dozda 150 mg gün $^{-1}$ pregabalin tedavisi başlandı. Takiplerinde, 2 aylık tedavi sonrasında ağrı tamamen kayboldu.

\section{TARTIŞMA}

Epidural steroid enjeksiyonunun (ESE) epidural boşluktaki inflamasyonu ve spinal nöron hiperaktivitesini azaltarak, etkilenmiş sinir köküne bağlı oluşan ağrıyı azalttığı düşünülmektedir. Ancak ESE sırasında uygulanacak steroidin yoğunluğu ve volümü konusunda düşünce birliği henüz oluşmamıştır. ESE başarı oranı \%20-81 gibi geniş bir aralıkta değişim göstermektedir ${ }^{(7)}$. Başarılı bir ESE uygulamasının bel bölgesinde oluşturduğu rahatlama ve fonksiyonel düzelmenin etkisi 12 ay kadar sürebilmektedir (7). Olgumuzda, ESE uygulamasıyla, söz edilen klinik iyileşme sağlanmış olmakla birlikte, nadir bir komplikasyon olmasına rağmen, Herpes Zoster ve buna bağlı olarak da PHN gelişmiştir.

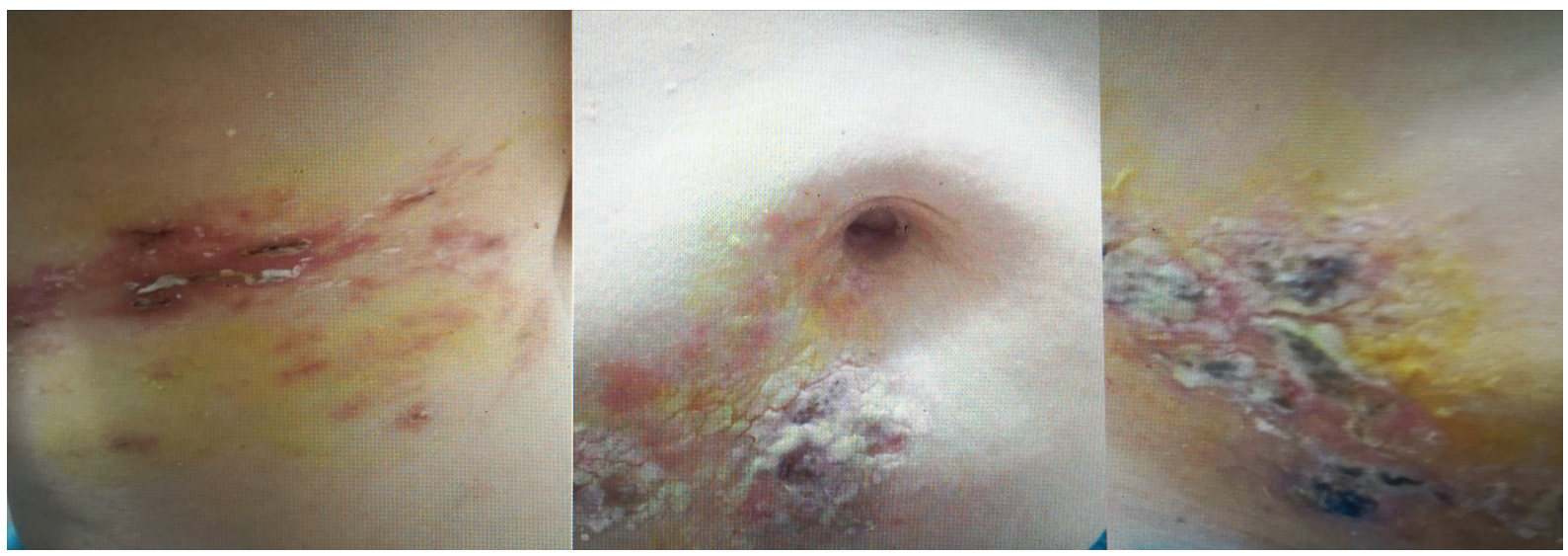

Resim 1. Olgunun alt torakal sinir dermatomu bölgesinde gelişen kurutlu makülopapüler ve vezikülopüstüler döküntüleri 
$\mathrm{HZ}$ enfeksiyonu arka kök gangliyonlarında latent olarak kalan $\mathrm{HZ}$ virüsünün, özellikle malignite, enfeksiyon veya ilaç kullanımı gibi bağışıklık sisteminin baskılandığı hastalarda reaktivasyonu sonucu oluşur ${ }^{(6)}$. Bu klinik tabloda enfekte kişiler ile karşılaşma öyküsü yoktur. Yaşla görülme sıklığı artar. HZ tanısı klasik prodromal ağrı-yanma ve veziküler döküntüler ile konur. Tek taraflı etkilenen dermatom boyunca döküntüler görülür. Hastaların \%50'sinde toraks bölgesi etkilenirken, \%10-15'inde trigeminal sinir etkilenir ${ }^{(6,8)}$. HZ enfeksiyonuna yakalanan hastaların $1 / 3^{\prime}$ inde PHN tablosu görülür ${ }^{(8)}$. Hastalığa bağlı gelişen deri lezyonları iyileştikten aylar ve hatta yıllar sonra bile PHN ağrısı devam edebilmektedir. İmmunitesi ilaç veya hastalık nedeniyle zayıflamış kişilerin PHN gelişimi açısından risk grubu oluşturduğu ileri sürülmüşse de risk bazı çalışmalarda sağlam bireylerden farklı bulunmamıştır. Bununla birlikte, diyabeti olanlarda da PHN gelişimi sık olarak bildirilmiştir (9). Literatürde PHN'nin tedavisi için epidural steroid kullanımına dair pek çok yayın varken paradoksal bir şekilde, olgumuzdaki gibi stereoid enjeksiyonuna bağlı PHN yalnızca 2 olguda bildirilmiştir ${ }^{(4,5)}$. Sistemik hiçbir rahatsızlığı olmadığı bildirilen bu 2 olgu raporunda ağrı tedavisi için ESE uygulanmış ve 4-7 gün sonra olgularda $\mathrm{HZ}$ enfeksiyonu gelişmiştir. ESE ile uygulanan metilprednizolon dışında olguların hiçbirinde immün sistemi baskılayarak $\mathrm{HZ}$ enfeksiyonuna neden olabilecek başka bir risk faktörü belirlenememiştir ${ }^{(4,5)}$.

Yapılan çalışmalarda, $\mathrm{HZ}$ tedavisinde kullanılan antiviral ilaçların PHN insidasını azaltıp azaltmadığına dair bilgiler çelişkilidir ${ }^{(10)}$. İmmün süpressif tedavi ile lösemi ve lenfomalar gibi ciddi immun supresyona neden olan hastalıkların varlığı PHN gelişimi için en güçlü risk faktörü olarak bildirilmiştir ${ }^{(11)}$. Diğer risk faktörleri ise romatoid artrit, sistemik lupus eritramatozus gibi otoimmun hastalıklar, KOAH, depresyon, astım, obezite, böbrek yetersizlikleri gibi kronik hastalıkları içermektedir ${ }^{(11)}$. Akut HZ enfeksiyonu olan hastalarda prodromal ağrı ve döküntülerin ilerleyici nitelikte olması PHN için bir yatkınlık oluşturabilir. İleri yaş da PHN riskini arttıran önemli bir faktördür. Özellikle 50-79 yaş arasında riskin arttığı ve 80 yaşından sonra ise yine azaldığı bildirilmiştir ${ }^{(12)}$. Olgumuz kronik böbrek yetmezliği nedeniyle 7 yıldır rutin olarak hemodiyaliz tedavisi aldığı ve 73 yaşında olduğu için PHN gelişimi açısından risk teşkil eden grupta yer almakta idi.
Otoimmun faktörler ve immün yetersizliklerin PHN gelişiminde risk faktörü olması, henüz tam anlaşılamamış olan PHN'nin patofizyolojik mekanizmasına ışık tutabilir. PHN etiyolojisinde 2 anahtar hipotez ortaya atılmıştır. Bunlar, $\mathrm{HZ}$ virüsünün giderek direnç kazanmasına bağlı olarak yarattığı klinik tablonun ilerleyici olması ya da ağrının algılanmasında yarattığı nöronal uyarılabilirlik ve değişikliktir ${ }^{(13)}$.

Pregabalin, analjezik, anksiyolitik ve antikonvülzan özellikleri de olan bir gama aminobütirik asit analoğudur. Son yıllarda postherpetik nevralji gibi nöropatik ağrı tedavisinde diğer ajanlara üstünlüğü kanıtlanamamıs olsa da sık kullanılmaktadır ${ }^{(14)}$. Olgumuzda da postherpetik nevralji tedavisinde pregabalin kullanılarak mevcut ağıı başarıyla tedavi edilmiş̧ir.

Son yıllarda $\mathrm{HZ}$ aşısının yaşlı ve risk altındaki immunsupressif hastalarda profilaktik olarak uygulanmasının hem HZ hem PHN sıklığını azaltabileceğine dair pek çok çalışma mevcuttur ${ }^{(13,15)}$.

Sonuç olarak, ESE uygulaması bel ağrılarının tedavisinde sıklıkla kullanılan bir yöntemdir. Olgumuzda, ESE uygulandıktan sonra, bir hafta içerisinde $\mathrm{HZ}$ enfeksiyonu gelişmiştir. Buradaki zamansal ilişkiyi dikkate aldığımızda, bu enfeksiyonun oluşumuna zemin oluşturabilecek en önemli risk faktörü olarak, epidural alana uygulanan steroid enjeksiyonu düşünülmelidir. Özellikle KBY'li hastalarda zayıflamış olan hücresel savunma sisteminin, sistemik veya lokal kortikosteroid kullanımı ile daha da baskılanabileceği, bunun da vücutta latent enfeksiyonların reaktivasyonuna neden olabileceği göz önünde bulundurulmalıdır.

Çıkar Çatışması: Yazarlar herhangi bir çıkar çatışması bildirmemişlerdir.

Finansal Destek: Yoktur.

Hasta Onamı: Olgudan tıbbi bilgilerinin kullanımı için onam alınmıştır.

Conflict of Interest: Authors do not report any conflict of interest.

Funding: None.

Informed Consent: The patient was informed about the use of medical information. 


\section{KAYNAKLAR}

1. Sarı S, Aydın ON, Güleser G, Kurt I, Turan A. Effect of transforaminal anterior epidural steroid injection on neuropathic pain, quality of sleep and life. Ağrı. 2015;27:83-8.

https://doi.org/10.5505/agri.2015.91489

2. Evans W. Intrasacral epidural injection in the treatment of sciatica. Lancet. 1930;2:1225-9. https://doi.org/10.1016/S0140-6736(00)86498-3

3. Vorobeychik Y, Sharma A, Smith CC, et al. The Effectiveness and Risks of Non-Image-Guided Lumbar Interlaminar Epidural Steroid Injections: A Systematic Review with Comprehensive Analysis of the Published Data. Pain Medicine. 2016;17:2185-2202.

https://doi.org/10.1093/pm/pnw091

4. Parsons SJ, Hawboldt GS. A previously Unrecognized Complication of Epidural Steroids in the Treatment of Complex Regional Pain Syndrome. Journal of Pain and Symptom Management. 2003;25:198-9. https://doi.org/10.1016/S0885-3924(02)00707-8

5. Szokol JW, Gilbert HC. A herpes zoster outbreak temporarily associated with an epidural steroid injection, Regional Anesthesia and Pain Medicine. 1998;23:328. https://doi.org/10.1016/S1098-7339(98)90069-4

6. Weinberg JM. Herpes zoster: epidemiology, natural history, and common complications. J Am Acad Dermatol. 2007; 57:130-5. https://doi.org/10.1016/j.jaad.2007.08.046

7. Manchikanti L, Knezevic NN, Boswell MV, et al. Epidural injections for lumbar radiculopathy and spinal steno- sis: a comparative systematic review and metaanalysis. Pain Physician. 2016;19:365-410.

8. Tyring SK. Management of herpes zoster and postherpetic neuralgia. J Am Acad Dermatol. 2007;57:136-42. https://doi.org/10.1016/j.jaad.2007.09.016

9. Akyol DT, Utaf S. Postherpetik Nevralji ve Tedavisi. TÜRKDERM. 2002;36:298-302.

10. Chen N, Li Q, Yang J. Antiviral treatment for preventing postherpetic neuralgia. Cochrane Database Syst Rev. 2014;2:CD006866. https://doi.org/10.1002/14651858.CD006866.pub3

11. Forbes HJ, Bhaskaran K, Thomas SL, et al. Quantification of risk factors for postherpetic neuralgia in herpes zoster patients. Neurology. 2016;87:94-102. https://doi.org/10.1212/WNL.0000000000002808

12. Gauthier A, Breuer J, Carrington D, et al. Epidemiology and cost of herpes zoster and post-herpetic neuralgia in the United Kingdom. Epidemiol Infect. 2009;137:3847. https://doi.org/10.1017/S0950268808000678

13. Harpaz R, Nagel MA, Schmader K, et al. Roundtable on postherpetic neuralgia: what, why, how long and what's next? Popul Health Manag. 2012;15:385-90. https://doi.org/10.1089/pop.2012.1562

14. Ifuku M, Iseki M, Hidaka I, et al. Replacement of gabapentin with pregabalin in postherpetic neuralgia therapy. Pain Med. 2011;12:1112-6. https://doi.org/10.1111/j.1526-4637.2011.01162.x

15. Esposito S, Principi N. Herpes zoster prevention: A difficult problem to solve. Vaccine. 2018;36:5442-48. https://doi.org/10.1016/j.vaccine.2017.07.099 